\title{
Pheochromocytoma: A Clinicopathologic Case Series
}

\author{
I Gusti Ayu Sri Mahendra Dewi ${ }^{1}$, Desak Putu Gayatri Saraswati Seputra ${ }^{2}$ \\ ${ }^{1}$ Anatomical Pathology Department, Medicine Faculty of Udayana University, Sanglah Hospital, Denpasar, Bali, Indonesia \\ 2 Internship Doctor, Ari Canti Hospital, Gianyar, Bali, Indonesia
}

\section{ARTICLE INFO}

Received : 20 September 2019

Reviewed : 10 October 2019

Accepted : 27 December 2019

\section{Keywords:}

adrenal, clinicopathology,

pheochromocytoma

\begin{abstract}
A BSTRACT
Introduction: Pheochromocytoma is a rare neuroendocrine tumor derived from the chromaffin cells of adrenal medulla. The incidence ranges from $0.005 \%$ to $0.1 \%$ in the general population.

Case Presentation: This case series reported 4 patients with pheochromocytoma who were diagnosed at Sanglah General Hospital Denpasar over a period of three years (2017-2019). The age ranged from $15-59$ years with the mean age of $41 \pm 18.9$ years. A similar proportion was found for both sexes. Clinical features include lumps, headaches, flank region pain, palpitations and cold sweat. Hypertension was found in 3 cases. Local examination revealed the solid mass in the flank region in all cases; enlarged lymph nodes were found in one case, namely in the paraaortic region. Abdominal MSCT examination findings showed: a solid mass with cystic components in suprarenal; sizes ranging from $1.9 \times 2.6 \times 2.2 \mathrm{~cm}$ to $21.6 \times 14.3 \times 17.8 \mathrm{~cm}$; bilateral ( 1 case), unilateral ( 3 cases); contrast enhancement and hypervascularization, without calcification (4 cases); central necrotic (1 case). All patients underwent radical adrenalectomy. Microscopic features showed the tumor mass which consisted of the proliferation of chromaffin cells forming alveolar (Zellballen) and solid nest patterns separated by capillary blood vessels. The cells were polygonal-shaped with clear cytoplasm, round-shaped nucleus, and moderate pleomorphic. Mitosis was not found. These histomorphologic findings supported the diagnosis of pheochromocytoma.
\end{abstract}

Conclusions: Diagnosis and optimal treatment plans can be established through rapid and precise recognition of pheochromocytoma in order to achieve better outcomes.

\author{
*Corresponding author: \\ I Gusti Ayu Sri Mahendra Dewi \\ Anatomical Pathology Department, \\ Medicine Faculty of Udayana \\ University, Sanglah Hospital, \\ Denpasar, Bali \\ mahendradewi@rocketmail.com
}

complications. This condition may also cause morbidity due to the mass effect on surrounding tissues [5].

Rapid and precise recognition of pheochromocytomas is essential to make optimal diagnosis and treatment plans to achieve better outcomes. The authors report four patients with "pheochromocytoma" registered at Sanglah General Hospital Denpasar, a tertiary hospital in Bali from 2017 to 2019.

\section{CASE PRESENTATION}

We report several patients diagnosed with pheochromocytoma at Sanglah General Hospital Denpasar for three years (2017 to 2019 period). Information regarding clinical features, imaging and histopathological findings were obtained for each patient. The definitive diagnosis was established based on the histopathological examination through $\mathrm{H} \& \mathrm{E}$ staining.

Four cases were diagnosed in a three-year period. One case belongs to the pediatric group. The age ranged from 15 to 59 years with the mean age of $41 \pm 18.9$ 
years. A similar proportion was found for both sexes. Clinical symptoms that were obtained from the patients include lumps (4 cases), headache (2 cases), flank region pain (1 case), palpitations (1 case), and cold sweat (1 case).

Hypertension was found in 3 cases with a range of findings of 140-180 / 100-130 mmHg. A hypertensive crisis was found at the initial blood pressure examination in the Emergency Unit in 1 case (male, 15 years old), where the blood pressure was $180 / 130 \mathrm{mmHg}$.

The examination of the local status in all cases found a well-demarcated solid mass in the flank region with or without tenderness. Lymph node enlargement was present in one case, namely in the paraaortic region.

An abdominal MSCT examination was performed in all cases. The solid mass with cystic components in suprarenal was found with sizes ranging from $1.9 \times 2.6 \times$ $2.2 \mathrm{~cm}$ to $21.6 \times 14.3 \times 17.8 \mathrm{~cm}$. Bilateral masses were found in only 1 case, while 3 other cases were unilateral. All masses showed contrast enhancement and hypervascularization without calcification appearance. Necrotic features at the center of the mass were found in one of the cases. Paraaortic lymphadenopathy was found in one case in the form of multiple nodules with the largest diameter measuring $\pm 3.36 \times 3.04 \mathrm{~cm}$ (Figure 1).

The four cases were diagnosed with the suprarenal tumor and surgical procedures in the form of radical adrenalectomy through laparotomy or laparoscopy. The adrenal gland masses were resected and sent to the Anatomical Pathology Laboratory. The diagnosis was confirmed for each case through the histopathological examination which shows a tendency towards pheochromocytoma. Microscopic images of tumors showed adrenal tissues containing well-defined tumor masses. Tumors consisted of the proliferation of chromaffin cells forming an alveolar (Zellballen) pattern and solid nests separated by capillaries. The cells were polygonal in shape with clear cytoplasm, round nucleus and moderate pleomorphic. Mitosis was not found (Figure 2).
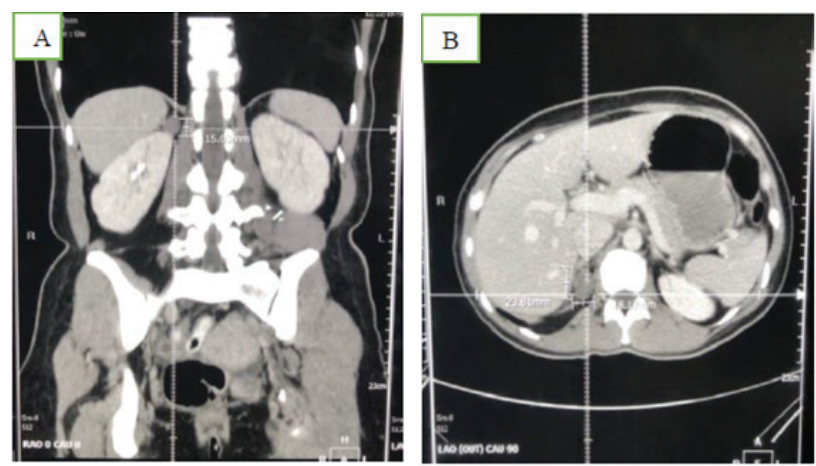

Figure 1. Overview of abdominal CT examination with contrast agent, (A) Coronal section, and (B) Axial section shows visible mass in right suprarenal with a size of $1.9 \times 6 \times 2.2 \mathrm{~cm}$.
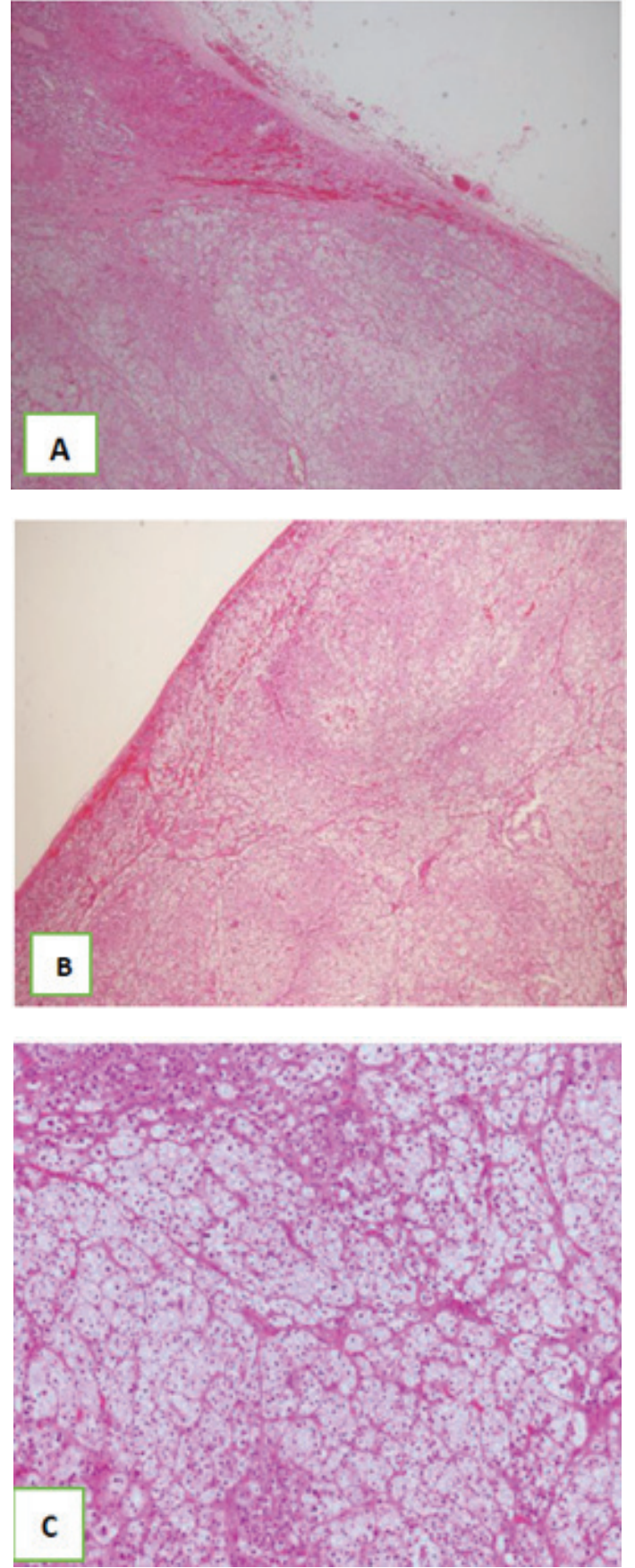

Figure 2. The microscopic finding shows adrenal tissue containing tumor with a well-defined border, consists of a proliferation of cells forming a pattern of solid nests separated by capillaries. Cell morphology is polygonal with clear cytoplasm, round-shaped nucleus and moderate pleomorphic. Mitosis is not found. No visible vascular invasion (A) with 100x magnification, (B) $100 x$ magnification, and (C) 400x magnification. (H\&E)

\section{DISCUSSION}

Pheochromocytoma is a neuroendocrine tumor that is quite rare. The incidence ranges from $0.005 \%$ to $0.1 \%$ in the general population. This condition is more often 
found in the age group of $40-50$ years [2,3]. This case series showed a similar finding, where the mean age of the cases was $41 \pm 18.9$ years. Three out of the total cases were included in the age group of 40-50 years. Approximately $10-20 \%$ of cases of pheochromocytoma are diagnosed in childhood with an average age of 11 years [4]. This case series reported 1 case of pediatric with pheochromocytoma that was aged 15 at the time of diagnosis. Literature states the same frequency for both sexes, which shows an agreement with the findings in this case series [2].

Symptoms and signs of pheochromocytoma often resemble other clinical conditions. The classic triad of pheochromocytoma, which is diaphoresis, palpitations and headaches, is reported to have a sensitivity of $67 \%$. This number may even reach $91-94 \%$ if accompanied by hypertension. Studies show the clinical manifestation of pheochromocytoma patients varies in the following proportions: palpitations (58.1\%), headache (51.9\%), sweating $(48.8 \%)$, anxiety (35.3\%), tremors (25.6\%), nausea $(22.4 \%)$, shortness of breath $(16.6 \%)$, vertigo (16.5\%), abdominal pain (16.1\%), paresthesia (11.9\%), chest pain $(11,8 \%)$, diarrhea/constipation (10.6\%), syncope $(5.1 \%)$, and fever (2\%) [3]. Other complaints in less frequent cases are generally related to the effect of the tumor mass (e.g. local pain) [4]. The main complaints in this case series included lumps (4 cases), headache (2 cases), flank region pain (1 case), palpitations (1 case), and cold sweat (1 case).

The incidence of pheochromocytoma ranges from $0.1 \%$ to $0.2 \%$ of the hypertensive adult population; however, this figure may only represent $50 \%$ of all pheochromocytoma patients because some patients have paroxysmal hypertension or even normotension [3]. Approximately $50 \%$ of pheochromocytoma patients have paroxysmal hypertension, $40 \%$ have persistent systemic arterial hypertension and 5-15\% are normotensive [2]. Hypertension was found in 3 patients of the reported cases; the range of findings was $140-180 / 100-130 \mathrm{mmHg}$. One case even came with hypertensive crisis status. Given the sizeable proportion of paroxysmal hypertension or normotension in pheochromocytoma patients, blood pressure within normal limits at initial screening cannot rule out the absence of hypertension as a clinical manifestation of pheochromocytoma.

The radiological examination needs to be done to identify the location of the tumor. Computed Tomography (CT) scanning is the first choice of modality because of its superior spatial resolution compared to Magnetic Resonance Imaging (MRI) [6]. CT scan has a sensitivity of $90-100 \%$ and a specificity of $70-80 \%$ for detecting pheochromocytoma [2,5]. Pheochromocytoma on imaging often contains necrotic, cystic and/or hemorrhagic areas [4]. Smaller lesions tend to be solid, whereas larger lesions tend to be cystic or hemorrhagic. Macroscopic radiology features of pheochromocytoma include cystic, calcified, fibrotic and necrotic regions with internal hemorrhage [3]. This case series obtained radiological findings of abdominal MSCT in the form of solid masses with cystic components with sizes ranging from $1.9 \times 2.6 \times 2.2 \mathrm{~cm}$ to $21.6 \times 14.3 \times 17.8 \mathrm{~cm}$. All masses showed contrast enhancement and hypervascularization, without calcification appearance. Necrotic features at the center of the mass were found in one of the cases. Bilateral masses were found in only 1 case, while 3 other cases were unilateral. The literature states that $10 \%$ of pheochromocytoma cases are bilateral and are considered as a feature of condition with familial etiology [2,5]. Paraaortic lymphadenopathy was found in one case.

The main treatment modality for pheochromocytoma is through surgical resection. Minimally invasive adrenalectomy with laparoscopy is recommended for most cases of pheochromocytoma. Another surgical modality is through open resection. Open resection provides a broader view of the surgical field and is therefore preferred in cases of large pheochromocytoma $(>9 \mathrm{~cm})$ to ensure complete resection of the tumor $[2,3,4]$. Radical adrenalectomy procedures were performed in all reported cases. Three patients were treated with surgical procedures through laparotomy, while 1 case with a smaller tumor size of $1.9 \times 2.6 \times$ $2.2 \mathrm{~cm}$ was treated through laparoscopy.

Pheochromocytoma tumor cells microscopically consist of polygonal cells that form alveolar, trabecular, or solid patterns. Alveolar patterns are formed from cells surrounded by structures that are rich in capillary vessels, which resemble well-demarcated nests or often referred to as Zellballen and are bound by amyloidcontaining fibrovascular stroma $[7,8]$. The size and shape of these tumor cells vary and have smooth granular basophilic or amphophilic cytoplasm. Nuclei are usually round or oval in shape with prominent nucleoli and may contain inclusion structures resulting from deep cytoplasmic invagination. This morphology corresponds to the microscopic findings of the tumor in the reported cases.

The prognosis of pheochromocytoma depends on the resectability and genetic profile. The 5-year survival rate in pheochromocytoma patients, if present with metastasis, is $34-60 \%$. Survival becomes $<5$ years when metastases occur in the liver or lungs and longer if there is bone metastasis. Local invasion can provide a long survival rate if complete excision is carried out (9).

\section{CONCLUSIONS}

Pheochromocytoma is a neuroendocrine tumor derived from chromaffin cells of adrenal medulla. The incidence is indeed quite rare as we only found 4 cases 
of pheochromocytoma in a 3-year period. This case series reported pheochromocytoma in 4 patients who were diagnosed based on clinical, radiological and histopathological findings. Early diagnosis and treatment of pheochromocytoma are crucial to achieving better outcomes.

\section{DECLARATIONS}

\section{Competing of Interest}

The authors declare no competing interest in this study.

\section{Acknowledgement}

The authors wish to thank the Head of Anatomical Pathology Laboratory Sanglah Hospital Denpasar and all staff that contribute to the completion of this case series.

\section{REFERENCES}

1. Conzo G, Pasquali D, Colantuoni V, Circelli L, Tartaglia E, Gambardella C, Napolitano S, Mauriello C, Avenia N, Santini L, Sinisi AA. Current concepts of pheochromocytoma. Int J Surg. 2014:469-74.

2. Sánchez-Turcios RA.Pheochromocytomas: Diagnosis and treatment. Rev Mex Cardiol. 2015;26(3):118-24.
3. Farrugia FA, Martikos G, Tzanetis P, Charalampopoulos A, Misiakos E, Zavras N, Sotiropoulos D. Pheochromocytoma, diagnosis and treatment: Review of the literature. Endocr Regul. 2017;51(3):168-81.

4. Waguespack SG, Rich T, Grubbs E, Ying AK, Perrier ND, Ayala-Ramirez M, Jimenez C. A current review of the etiology, diagnosis, and treatment of pediatric pheochromocytoma and paraganglioma. J Clin Endocrinol Metab. 2010; 95(5):2023-37.

5. Lenders JW, Duh $Q$, Eisenhofer $G$, Gimenez-Roqueplo A, Grebe SK, Murad MH, Naruse M, Pacak K, Young WF. Pheochromocytoma and paraganglioma: An endocrine society clinical practice guideline. J Clin Endocrinol Metab. 2014;99: 1915-42.

6. Lenders JW, Eisenhofer G. Update on modern management of pheochromocytoma and paraganglioma. Endocrinol Metab. 2017;32:152-61.

7. Rosai J. Adrenal gland and other paraganglia. In: Goldblum JR, Lamps LW, McKenney JK, Myers JL, editors. Rosai and Ackerman's Surgical Pathology. 11th Edition. Philadelphia: Elsevier;2018. p.1057-84.

8. Mangray S, DeLellis RA. Adrenal glands. In: Mills SE, editor. Sternberg's diagnostic surgical pathology. 6th Edition. Philadelphia: Wolters Kluwer Health;2015. p.1723-66.

9. Trischler AS, de Krijger RR, Grill A, Kawashima A, Kimura N. Phaeochromocytoma. In: Lloyd TV, Osamura RY, Kloppel G, Rosai J editors. WHO classification of tumours of endocrine organs. 4th Edition. Lyon: IARC;2014. p.183-9. 